\title{
Dynamic modeling and controllability analysis of an ethanol reformer for fuel cell application
}

Vanesa M. García $^{\text {a*}}$, Eduardo López $^{\text {b,c }}$, Maria Serra ${ }^{\text {a }}$, Jordi Llorca ${ }^{b}$, Jordi Riera $^{a}$

${ }^{a}$ Institut de Robòtica i Informàtica Industrial (CSIC-UPC). Llorens i Artigas 4-6, 08028

Barcelona, Spain.

${ }^{\mathrm{b}}$ Institut de Tècniques Energètiques. Universitat Politècnica de Catalunya.

Diagonal 647, ed. ETSEIB. 08028 Barcelona, Spain.

${ }^{c}$ Planta Piloto de Ingeniería Química (CONICET-UNS). Camino de la

Carrindanga km7. 8000 Bahía Blanca, Argentina.

Keywords: Hydrogen production, Ethanol steam reforming, Sensitivity analysis, Controllability analysis.

\section{* Corresponding author:}

\section{Vanesa M. García}

Institut de Robòtica i Informàtica Industrial (CSIC-UPC)

Llorens i Artigas 4-6, 08028 Barcelona, Spain

Tel.: (+34) 934015805

Fax.: (+34) 934015750

e-mail:vgarcia@iri.upc.edu 


\begin{abstract}
This work presents a controllability analysis of a low temperature ethanol reformer based on a cobalt catalyst for fuel cell application. The study is based on a nonlinear dynamic model of a reformer which operates in three separate stages: ethanol dehydrogenation to acetaldehyde and hydrogen, acetaldehyde steam reforming, and water gas shift reaction. The controllability analysis is focused on the rapid dynamics due to mass balances and is based on a linearization of the complex non-linear model of the reformer. RGA, CN and MRI analysis tools are applied to the linear model suggesting that a good performance can be obtained with decentralized control for frequencies up to $0.1 \mathrm{rad} / \mathrm{s}$.
\end{abstract}

\title{
1. Introduction
}

Ethanol is a promising source of hydrogen as it is a renewable raw material when is obtained from biomass, and hence, research on catalytic steam reforming of ethanol and ethanol reformers is acquiring increasing interest. Ethanol reforming, as illustrated in Eq. (1), has been extensively studied over catalysts based on $\mathrm{Ni}, \mathrm{Ni} / \mathrm{Cu}, \mathrm{Co}$, and noble metals $(\mathrm{Pd}, \mathrm{Pt}, \mathrm{Rh}$ and $\mathrm{Ru})[1,2]$. The reaction is reversible and highly endothermic $\left(\Delta H_{298}^{\circ}=208.4 \mathrm{~kJ} \mathrm{~mol}^{-1}\right)$, which accounts for the requirement of operation temperatures usually above $873 \mathrm{~K}$. At such high temperatures ethanol is mainly reformed into a mixture of $\mathrm{H}_{2}$ and $\mathrm{CO}$, as shown in Eq. (2). As carbon monoxide is a strong poison for the anode's platinum catalyst of the fuel cell it is mandatory to pass the reformate through a water gas shift reactor [3-4], see Eq. (3), in order to generate further hydrogen 
and eliminate CO. However, cobalt-based catalysts are particularly suitable for ethanol steam reforming at lower temperatures, $623-673 \mathrm{~K}$, where the water gas shift reaction is very effective. For this reason, increasing attention is being focused on developing lowtemperature catalytic processes with cobalt catalysts, both in packed reactors [5-6] as well as in microreactors for portable applications [7-8].

$$
\begin{aligned}
& \mathrm{C}_{2} \mathrm{H}_{5} \mathrm{OH}+3 \mathrm{H}_{2} \mathrm{O} \rightarrow 6 \mathrm{H}_{2}+2 \mathrm{CO}_{2} \\
& \mathrm{C}_{2} \mathrm{H}_{5} \mathrm{OH}+\mathrm{H}_{2} \mathrm{O} \rightarrow 4 \mathrm{H}_{2}+2 \mathrm{CO} \\
& \mathrm{CO}+\mathrm{H}_{2} \mathrm{O} \leftrightarrow \mathrm{CO}_{2}+\mathrm{H}_{2}
\end{aligned}
$$

In a previous contribution, the authors reported results addressing the dynamic modeling of a three-module reactor for fuel cell hydrogen feeding [9]. Three specific catalysts were selected for each of the three modules of the reforming unit. Nanocrystalline $\mathrm{SnO}_{2}$ was used for the first step comprising ethanol dehydrogenation, while acethaldeyde steam reforming was performed in the second module with a $\mathrm{Co}(\mathrm{Fe}) / \mathrm{ZnO}$ catalyst doped with $\mathrm{Na}^{+}$. For the final water-gas shift step a reported kinetics for a commercial catalyst based on $\mathrm{Fe}_{2} \mathrm{O}_{3}-\mathrm{Cr}_{2} \mathrm{O}_{3}$ was selected [11]. Detailed kinetic experiments over well-defined samples for the first two stages of the process were reported, as well as fitted parameters for power-law type kinetic expressions to quantify the correspondent reaction rates. A dynamic mathematical model of the threestage reformer was presented as a tool for design of control-oriented devices. Monoliths were chosen to support the referenced catalysts. Fig. 1 shows a schematic representation of the three-staged reforming process. 
The present contribution exploits the mathematical model presented in the above-cited reference [9] to perform a controllability analysis of the reforming unit. While the overall aim of the project is the design of a control strategy of the complete system (reformer + fuel cell), this paper focuses on the analysis of the fast response of the reformer due to changes in flow/concentrations of the feed. Future work will address the design of temperature controllers and the integration of the reformer with the fuel-cell. The following sections comprise a description of the mathematical model of the reformer and the analysis methodology followed by sensitivity and controllability analyses.

\section{Non linear Model}

A one-dimensional, pseudo-homogeneous, non-steady-state model has been used to represent the dynamic behavior of the ethanol reforming reactor in the already referenced series of monolithic stages. 1-D pseudo-homogeneous models are usually selected for control-oriented applications to reduce the solving time of the equations system, [10]. The kinetic expressions for the reactions occurring in stages 1 and 3 are taken from [9] and [11], respectively. However, a modification has been introduced in the present work regarding the system of reactions over the cobalt-based catalyst in bed 2. In fact, a parallel-series scheme is proposed to adjust the experimentally-observed product distribution, where acetaldehyde is reformed with steam towards carbon monoxide or carbon dioxide, which are consecutively balanced by the water-gas shift reaction:

$$
\mathrm{C}_{2} \mathrm{H}_{4} \mathrm{O}+\mathrm{H}_{2} \mathrm{O} \rightarrow 3 \mathrm{H}_{2}+2 \mathrm{CO}
$$




$$
\begin{aligned}
& \mathrm{C}_{2} \mathrm{H}_{4} \mathrm{O}+3 \mathrm{H}_{2} \mathrm{O} \rightarrow 5 \mathrm{H}_{2}+2 \mathrm{CO}_{2} \\
& \mathrm{CO}+\mathrm{H}_{2} \mathrm{O} \leftrightarrow \mathrm{CO}_{2}+\mathrm{H}_{2}
\end{aligned}
$$

First-order, power-law type kinetics were used for the three reactions. For reactions (4) and (5) a dependency on only acetaldehyde concentration is considered; kinetics for the water-gas shift reaction, Eq. (6), is based on the partial pressures of all the components involved in the reaction. By using a non-linear multi-parametric fitting routine, we obtained values of the reaction constants (at $673 \mathrm{~K}$ ) of $1.38 \times 10^{4} \mathrm{~mL} \mathrm{~g}_{\mathrm{cat}}{ }^{-1} \mathrm{~h}^{-1}, 1.52 \times 10^{4}$ $\mathrm{mL} \mathrm{g}_{\mathrm{cat}}{ }^{-1} \mathrm{~h}^{-1}$ and $9.70 \times 10^{2} \mathrm{~mol} \mathrm{~m}^{-3} \mathrm{~s}^{-1} \mathrm{~atm}^{-2}$, respectively.

The mass balance used to represent the non-steady-state reactor behavior, along with the corresponding initial and boundary conditions, is presented below:

Mass balance (component $j$ )

$$
\frac{\partial C_{j}}{\partial t}+\frac{\partial\left(v C_{j}\right)}{\partial z}=v_{j i} r_{i}
$$

Initial conditions $\quad C_{j}(0, x)=C_{j 0}(x) \quad \forall x \in[e, L], j=1 \ldots N$

Boundary conditions $\quad C_{j}(t, 0)=C_{j, e}(t) \quad \forall t>0$

The major assumptions underlying the model are the following:

- Gas properties are function of temperature and gas concentration. Ideal gas law is applicable due to the low operating pressure of ca. 1 bar. 
- The pressure drop in the reactors is assumed negligible due to the high void fraction of the monolithic structures.

- The use of low-diameter monoliths and optimized inlet distributors supports the assumption of 1-D model avoiding the occurrence of pronounced radial mass profiles.

The numerical solution of the set of partial differential equations, Eq. (7) to (9), is accomplished by its transformation into an ODE-system by discretization of the spatial derivative. To this end, backward finite differences have been selected (first-order, 38 equidistant discretization points). The resultant ODE equations $\left(198^{\text {th }}\right.$ order) are solved by an algorithm implemented in MATLAB $^{\circledR}$ (ODE45 Normand-Prince). Additional details regarding the mathematical model and its solving strategy can be found in [9].

\section{Methodology}

We consider the complete nonlinear model of the three-staged reforming process with two inputs and 6 outputs:

- Inputs: $\mathrm{F}_{\mathrm{C} 2 \mathrm{H} 5 \mathrm{OH}, \mathrm{e}}, \mathrm{F}_{\mathrm{H} 2 \mathrm{O}, \mathrm{e}}$

- Outputs: $\mathrm{F}_{\mathrm{C} 2 \mathrm{H} 5 \mathrm{OH}, \mathrm{L}}, \mathrm{F}_{\mathrm{C} 2 \mathrm{H} 4 \mathrm{O}, \mathrm{L}}, \mathrm{F}_{\mathrm{H} 2 \mathrm{O}, \mathrm{L}}, \mathrm{F}_{\mathrm{H} 2, \mathrm{~L}}, \mathrm{~F}_{\mathrm{CO}, \mathrm{L}}$ and $\mathrm{F}_{\mathrm{CO} 2, \mathrm{~L}}$

In this work, firstly a steady state sensitivity analysis is performed on the complete non linear model around a nominal operating point $\mathrm{OP}_{1}$. This operating point has been selected from appropriate conditions of the catalysts (which correspond to $\mathrm{T}_{\mathrm{s} 1}=648 \mathrm{~K}$, $\mathrm{T}_{\mathrm{s} 2}=673 \mathrm{~K}$ and $\left.\mathrm{T}_{\mathrm{s} 3}=633 \mathrm{~K}\right)$ and the dimension of each monolith to provide the required 
hydrogen flow to feed a 1kW PEM fuel cell. See [9] for more details. The static inputoutput non linearity characteristic is verified for different input levels.

One of the main goals of this work is to perform the controllability analysis of the reformer system. To this end, an accurate study of linearized versions of the model, at different operating points, is considered. The resulting MIMO linear systems are studied using different analysis tools. These tools are mathematic operators applied to the squared transfer functions of the linear system that provide relevant information such as stability, controllability, sensitivity, robustness, etc. They are applied to the process, without control, in order to characterize the controllability of the system as a property of the process itself. Preferred control structures to drive the system correctly are then deduced.

Three different controllability indexes are used [12]: the Relative Gain Array (RGA), the Condition Number (CN) and the Morari Resiliency Index (MRI). The RGA index is used to determine the interaction among control loops in a multivariable process. It is defined as the ratio of the open-loop gain for a selected output when all the other loops of the process are open, to its open-loop gain when all the other loops are closed. RGA of a complex non-singular matrix $\mathrm{M}$ is calculated as indicated in Eq. (10), where $\mathrm{x}$ denotes element by element multiplication (Hadamard product).

$$
\operatorname{RGA}(\mathrm{M})=\mathrm{M} \times\left(\mathrm{M}^{-1}\right)
$$

Pairings showing RGA close to unity matrix at frequencies around bandwidth are preferred. This rule favors minimal interaction between loops, which means 
independence of the loops. Being the loops independent, stability problems caused by interaction are prevented. Numbers around 0.5 indicate relevant interaction. The RGA indicates other useful control properties. One of the most important is that structures with large RGA elements around the bandwidth frequency are difficult to control due to sensitivity to input uncertainty [13].

The second controllability index analyzed is the condition number $(\mathrm{CN})$. It also proceeds from the singular value decomposition of the transfer function. The $\mathrm{CN}$ of a matrix is defined as the ratio between the maximum and minimum singular values and it is typically used for the selection of the control structure. It provides a numerical indication of the sensitivity balance in a multivariable system. Large condition numbers indicate unbalanced sensitivity and also sensitivity to changes in process parameters, Therefore, structures with small CNs are preferred.

Finally, the Morari Resillency Index (MRI) is the minimum singular value of the openloop transfer function, [12]. The MRI is a useful measure for determining whether acceptable control can be achieved. If it is less than one then poor control performances are expected. Large MRIs over the frequency range of interest are preferred. Usually, only the steady state value of these controllability indexes is regarded. However, their analysis in the frequency domain is important.

\section{Study of the static behaviour of the system}

To test the nonlinearity of the model we obtained steady state values of the reactor output flow rates $\mathrm{F}_{\mathrm{H} 2}, \mathrm{~F}_{\mathrm{CO}}$ and $\mathrm{F}_{\mathrm{CO} 2}$, following changes in ethanol input flow rate 
$\Delta \mathrm{F}_{\mathrm{C} 2 \mathrm{H} 5 \mathrm{OH}}$ and in water input flow rate $\Delta \mathrm{F}_{\mathrm{H} 2 \mathrm{O}}$ with respect to a nominal operating point, see $\mathrm{OP}_{1}$ in Table 1. In Figs. 2 to 5 the $\mathrm{H}_{2}$ yield, $\eta^{\mathrm{H} 2}$ as defined in Eq. (11), ethanol conversion, $x_{\mathrm{C} 2 \mathrm{H} 5 \mathrm{OH}}$ defined as shown in Eq. (12), and acetaldehyde conversion, $x_{\mathrm{C} 2 \mathrm{H} 4 \mathrm{O}}$, see Eq. (13), are plotted against the changes performed in $\mathrm{F}_{\mathrm{H} 2}, \mathrm{~F}_{\mathrm{CO}}, \mathrm{F}_{\mathrm{CO} 2}$ by applying successive steps of $+10 \%$. The results have been represented according to the following input increases:

- $\Delta \mathrm{F}_{\mathrm{C} 2 \mathrm{H} 5 \mathrm{OH}}: 10 \%$ Ethanol input increase while keeping the nominal water input flow rate $\left(\mathrm{F}_{\mathrm{H} 2 \mathrm{O}}=0.008210 \mathrm{~mol} / \mathrm{s}\right)$.

- $\Delta \mathrm{F}_{\mathrm{H} 2 \mathrm{O}}: 10 \%$ Water input increase while keeping the nominal ethanol input flow rate $\left(\mathrm{F}_{\mathrm{C} 2 \mathrm{H} 5 \mathrm{OH}}=0.001337 \mathrm{~mol} / \mathrm{s}\right)$.

- $\Delta \mathrm{F}_{\mathrm{H} 2 \mathrm{O}}$ and $\Delta \mathrm{F}_{\mathrm{C} 2 \mathrm{H} 5 \mathrm{OH}}$ : Both water input and ethanol inputs simultaneously $10 \%$ increases in both.

The hydrogen yield $\eta^{\mathrm{H} 2}$ is used to measure the effectiveness of the reforming process. It is calculated as the ratio between the hydrogen molar flowrate at the outlet of stage 3 and the theoretical hydrogen production:

$$
\eta^{H 2}=\frac{F_{H 2, L}}{6 F_{C 2 \mathrm{HSOH}, e}}
$$

Ethanol and Acetaldehyde conversions, in stage $1\left(x_{\mathrm{C} 2 \mathrm{H} 5 \mathrm{OH}}\right)$ and stage $2\left(x_{\mathrm{C2H} H \mathrm{O}}\right)$ are calculated through the following definitions:

$$
x_{\mathrm{C} 2 \mathrm{H} 5 \mathrm{OH}}=1-\frac{F_{\mathrm{C} 2 \mathrm{H} 5 \mathrm{OH}, \mathrm{L}}}{F_{\mathrm{C} 2 \mathrm{H} 5 \mathrm{OH}, \mathrm{e}}}
$$




$$
x_{C 2 \mathrm{H} 4 \mathrm{O}}=1-\frac{F_{C 2 \mathrm{H} 4 \mathrm{O}, \mathrm{L}}}{F_{\mathrm{C} 2 \mathrm{H} 4 \mathrm{O}, e}}
$$

Fig. 2 shows that the static gains in $\mathrm{F}_{\mathrm{H} 2}$ are almost linear positive for $\mathrm{F}_{\mathrm{C} 2 \mathrm{H} 5 \mathrm{OH}}$ and for simultaneous $\mathrm{F}_{\mathrm{H} 2 \mathrm{O}}$ and $\mathrm{F}_{\mathrm{C} 2 \mathrm{H} 5 \mathrm{OH}}$ increases. However, the static gain is negative when only $\Delta \mathrm{F}_{\mathrm{H} 2 \mathrm{O}}$ is performed. Regarding the hydrogen yield, the slope observed is steeper for perturbations in the input water flow rate than in the ethanol input flow rate. This behaviour is ascribed to higher drops in residence times (note the feed ratio $\mathrm{H}_{2} \mathrm{O}: \mathrm{C}_{2} \mathrm{H}_{5} \mathrm{OH}$ of $6: 1$ in $\left.\mathrm{OP}_{1}\right)$

Fig. 3 shows that the behavior of the $\mathrm{F}_{\mathrm{CO}}$ is strongly nonlinear with $\Delta \mathrm{F}_{\mathrm{C} 2 \mathrm{H} 5 \mathrm{OH}}$, while Fco is almost constant when $\mathrm{F}_{\mathrm{H} 2 \mathrm{O}}$ and $\mathrm{F}_{\mathrm{C} 2 \mathrm{H} 5 \mathrm{OH}}$ increase simultaneously. The negative slope of $\mathrm{F}_{\mathrm{CO}}$ with $\Delta \mathrm{F}_{\mathrm{H} 2 \mathrm{O}}$ is due to a greater extent of the water-gas shift reaction.

Carbon dioxide flow rate behaviour for perturbations in ethanol and water inputs is reported in Fig. 4. As also shown for $\mathrm{CO}, \mathrm{CO}_{2}$ flow rates increase due to higher partial

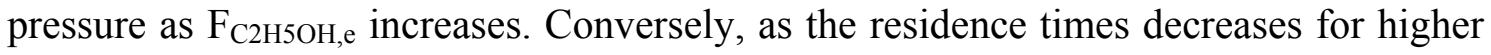
water inputs, drops of $\mathrm{F}_{\mathrm{CO} 2}$ are observed.

Fig. 5 reports ethanol and acetaldehyde conversion trends for the same variations in the inlet flows as reported above. Minimum ethanol and acetaldehyde conversions of ca. $90 \%$ are required for an appropriate closure of the economical balance of the system, as no recycling of unreacted products is planned. As observed in Fig. 5, higher drops in conversion are verified following increases in space velocities. In contrast, the variations in the ethanol feed fulfil the restriction of minimum conversion requirement. 
Table 1 summarizes the performance of the reforming unit at different operating points; results were obtained by using the detailed non linear model described in Eq. (7) to (9). When the reactor is fed with a higher flow rate of water, $\mathrm{OP}_{3}$ and $\mathrm{OP}_{4}$, the $\mathrm{H}_{2}$ yield diminishes. The advantage, however, is a marked decrease of the $\mathrm{CO}$ molar fraction output, $\mathrm{y}_{\mathrm{CO}}, \mathrm{L}$. We can also observe that it is possible to improve significantly the conversion of stage $1, x_{\mathrm{C} 2 \mathrm{H} 5 \mathrm{OH}}$, by increasing the operating temperature, $\mathrm{OP}_{9}$. In this case a relative good yield is obtained, although the molar fraction $\mathrm{y}_{\mathrm{CO}, \mathrm{L}}$ also increases. We observe that in $\mathrm{OP}_{5}$, with a large $\Delta \mathrm{F}_{\mathrm{C} 2 \mathrm{H} 5 \mathrm{OH}}$ from $\mathrm{OP}_{1}$, the hydrogen yield diminishes and $\mathrm{y}_{\mathrm{CO}}$ increases significantly. The best performance, with respect to the production of hydrogen $\left(\mathrm{F}_{\mathrm{H} 2, \mathrm{~L}}\right)$ corresponds to the operation points $\mathrm{OP}_{2}, \mathrm{OP}_{4}$, and $\mathrm{OP}_{5}$. Among these, $\mathrm{OP}_{4}$ is preferred as less $\mathrm{CO}$ is generated, in agreement with PEMFC feed restrictions.

\section{Controllability Analysis}

\subsection{Analysis of Linearized Models}

Linear models have been obtained by linearising the complete nonlinear model around the different operating points. To derive the linear models, SIMULINK ${ }^{\circledR}$ has been employed because it is integrated in MATLAB which provides an extensive range of tools. Unfortunately the accurate linearization tool supplies a state space matrix of the system with a very large dimension. Thus, a model reduction strategy has been applied to transform the original model into a simplified form with lower order while preserving the dynamic characteristics of the original high-order system [14]. 
Within the Model Order Reduction (MOR) algorithms for Linear Time-Invariant systems, supplied by MATLAB, the following methods can be distinguished: Balanced MOR based on Hankel Norm Approximation, Proper Orthogonal Decomposition, and MOR algorithms based on Kriol subspace methods.

The Balanced MOR technique was used here to achieve such task directly from the $198^{\text {th }}$ order model. Balanced truncation of the $198^{\text {th }}$ order model was achieved by using the function "balred" of the MATLAB Robust Control System Toolbox. It computes a $k^{\text {th }}$ order model given by:

$$
G_{m}=C_{m}\left(I s+A_{m}\right)^{-1} B_{m}+D_{m}
$$

of a possibly non-minimal and not necessarily stable $\mathrm{n}^{\text {th }}$ order system described by

$$
\begin{aligned}
& G=C(I s+A)^{-1} B+D \\
& \left\|G(j w)-G_{m}(j w)\right\|_{\infty} \leq \text { totbnd } \\
& \text { totbnd }=2 \sum_{i=k+1}^{n} s v h(i)
\end{aligned}
$$

Where $\mathrm{k}<\mathrm{n},\|.\|_{\infty}$ denotes the infinity norm of the difference between the full order and the truncated models, totbnd is the total error, and $s v h(i)$ denotes Hankel Singular Values of the full order model. Hankel Singular Values are defined as the square-roots of the eigenvalues of the system's reachability and observability grammians. They are considered a measure of the energy of each state in the system and an indication of its contribution to system characteristics. Thus, keeping only the states that contribute more to the system dynamics will reduce the order of the model while preserving most of its characteristics in terms of stability, time response and frequency response. Fig. 6 shows Hankel Singular Values of the $198^{\text {th }}$ order model and the detail of the first 20 . We have kept here 10 states in order to preserve the characteristics of the full order model. 
Fig. 7 compares the frequency response gains from the $198^{\text {th }}$ order model and those from the reduced $10^{\text {th }}$ order model. The outputs of the two models overlap quite well, leading to the conclusion that the $10^{\text {th }}$ order reduced model is a good approximation of the linearized $198^{\text {th }}$ order model.

\subsection{Input- Output Pairing}

One of the most common approaches to control a Multi-Input Multi-Output (MIMO) system is to use a diagonal controller, which is often referred to as a decentralized controller. The decentralized control works well if the system is close to diagonal, which means that the plant can be considered as a collection of individual single-input single-output (SISO) sub-plants with no interaction among them. In this case, the controller for each sub-plant can be designed independently. If the interaction between loops is large, then the performance of the decentralized controller may be poor.

Due to the behavior near the operating points the preferred pairing choices seems to be the $\mathrm{F}_{\mathrm{C} 2 \mathrm{H} 5 \mathrm{OH}, \mathrm{e}} \rightarrow \mathrm{F}_{\mathrm{H} 2, \mathrm{~L}}$ pair and the $\mathrm{F}_{\mathrm{H} 2 \mathrm{O}, \mathrm{e}} \rightarrow \mathrm{F}_{\mathrm{CO}, \mathrm{L}}$ pair. This pairing choice is also confirmed by the relative gain array (RGA) matrix of $G_{m}$. The frequency range of interest is given by the bandwidth frequency, normally defined as the frequency up to which control is effective [8]. The range of frequencies analysed in this work is $10^{-3}-10^{0}$ $\mathrm{rad} \mathrm{s}^{-1}$ because it is assumed that the bandwidth will be within this range. In Table 2 we show RGA at zero frequency for all operating points. Fig. 8 shows $\mathrm{RGA}_{11}$ values for all the different operating points over the frequency range of interest. 
The RGA can also be used to assess the loop interactions. Large off-diagonal elements of the RGA matrix indicate large loop interactions. A plot of the magnitude difference between the diagonal and off-diagonal elements of the RGA matrices is shown in Fig. 9 for $\mathrm{OP}_{1}, \mathrm{OP}_{3}$ and $\mathrm{OP}_{9}$. This figure shows that the interactions increase at high frequencies.

From steady state $(\mathrm{s}=0)$ to frequencies near $\omega=0.1 \mathrm{rad} / \mathrm{s}$, the $\mathrm{RGA}_{11}$ element is close to 1.26 (see table 2 or Fig. 8), indicating that the diagonal pairing suggested before could be used. However, at higher frequencies the off-diagonal RGA elements decrease to values around 0.6 , thus it is better to use a decentralized control for these frequencies. These conclusions are reinforced by observing that in Fig. 8 the three operating points show a similar positive value in the frequency range $10^{-3}-10^{-1}\left[\mathrm{rad} \mathrm{s}^{-1}\right]$, hence we can expect a good performance for the decentralized controller only for this frequency range.

In Figs. 10 and 11 the $\mathrm{CN}$ and the MRI of the properly scaled 2 input $\mathrm{x} 2$ output system are plotted, respectively. As mentioned before, the $\mathrm{CN}$ can be used as a controllability measure: If the $\mathrm{CN}$ is small the effects of process model mismatch are not likely to be important; conversely, for large $\mathrm{CN}$ there may be sensitivity to model mismatches. The best controllability is obtained for $\mathrm{OP}_{3}$, although other operating points, as $\mathrm{OP}_{4}, \mathrm{OP}_{6}$, and $\mathrm{OP}_{9}$, show a reasonable controllability. This suggests that increasing $\mathrm{F}_{\mathrm{H} 2 \mathrm{O}}$ can help to improve the performance of the control. The larger the value of MRI, the more controllable the process is. The lower values observed in Fig. 11 may indicate poor performance. 
From the study of the static behaviour of the system we can derive several considerations about the design of a control strategy for the reformer. From the analysis of Fig. 2, we could expect that, for the control of the $\mathrm{H}_{2}$ flow based on the manipulation of $\Delta \mathrm{F}_{\mathrm{C} 2 \mathrm{H} 5 \mathrm{OH}}$, a linear controller should have a good performance. However, such a controller would give an excessive $\mathrm{CO}$ flow rate when the operation is far from the nominal operating point, as shown in Fig. 3, and hence leading to an inappropriate performance of the reformer. If we desire to control $\mathrm{F}_{\mathrm{H} 2}$ and $\mathrm{F}_{\mathrm{CO}}$ at the same time, we could expect that a linear decentralized controller based on the manipulation of $\Delta \mathrm{F}_{\mathrm{H} 2 \mathrm{O}}$ and $\Delta \mathrm{F}_{\mathrm{C} 2 \mathrm{H} 5 \mathrm{OH}}$ would perform appropriately. To improve the efficiency, or the conversion rates $\left(x_{\mathrm{C} 2 \mathrm{H} 5 \mathrm{OH}}\right.$ and $\left.x_{\mathrm{C} 2 \mathrm{H} 4 \mathrm{O}}\right)$, more complex (coupled) controllers could be used. An alternative is employing additional control loops based on the temperature as the manipulating variable, which we are currently exploring.

\section{Conclusions}

The high non linear behaviour of the proposed three-staged reformer has been confirmed by the steady state analysis and it has been deduced that some operating points are more efficient. In particular, those with a larger water input flowrate allow the diminution of $\mathrm{CO}$. The same situation occurs for those operating points with temperatures slightly higher in the ethanol dehydrogenation stage and the acetaldehyde steam reforming stage. The controllability analysis with the RGA, CN and MRI suggests that for frequencies until $0.1 \mathrm{rad} / \mathrm{s}$ a decentralized control should present a good performance. Due to the high nonlinearities and the crossed interactions among reactions, a centralized controller, although more complex, should perform better if the 
reformer works far from the nominal operating point. This is the case for the envisaged application, $\mathrm{H}_{2}$ supply for a varying load fuel cell. Future work will address the design of these controllers taking into account both mass and energy balances.

\section{Acknowledgements}

This work has been funded partially by projects CICYT DPI2007-62966 and MEC ENE2006-06925 of the Spanish Government and by the Department of Universities, Investigation and Society of Information of the Generalitat de Catalunya.

\section{Nomenclature}

$C$ concentration $\left(\mathrm{mol} \mathrm{m}_{\mathrm{R}}{ }^{-3}\right)$

$F$ molar flowrate $\left(\mathrm{mol} \mathrm{s}^{-1}\right)$

$N$ number of components $(=6)$

$R \quad$ reaction rate $\left(\mathrm{mol} \mathrm{m}_{\mathrm{R}}^{-3} \mathrm{~s}^{-1}\right)$

$t$ time (s)

$T$ temperature $(\mathrm{K})$

$v \quad$ superficial velocity $\left(\mathrm{m} \mathrm{s}^{-1}\right)$

$x$ conversion

$z \quad$ axial coordinate $(\mathrm{m})$

$\eta^{H 2}$ hydrogen yield (\%)

y mole fraction

Subscripts

$0 \quad$ initial conditions $(\mathrm{t}=0)$

$e \quad$ reactor entrance

$L \quad$ reactor outlet

$g \quad$ gas

$i$ reaction number, $\mathrm{i}=1, \ldots, 3$ (ethanol decomposition, acetaldehyde reforming, water-gas shift, respectively) 


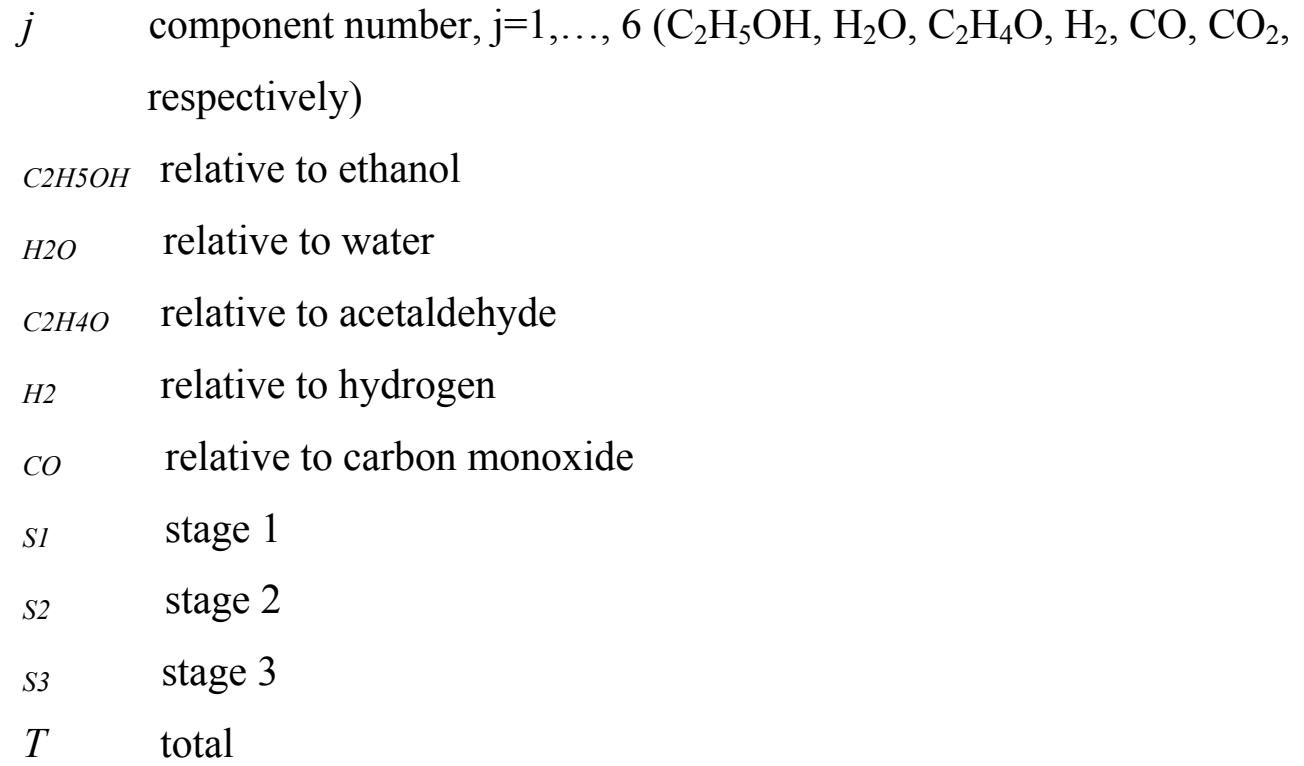

\section{Greek letters}

$\Delta H^{\circ}{ }_{298}$ heat of reaction $\left(\mathrm{J} \mathrm{mol}^{-1}\right)$

$\mathrm{v}_{j i} \quad$ stoichiometric coefficient of component $j$ in reaction $i$

\section{References}

[1] P.D. Vaidya and A.E. Rodrigues, Insight into steam reforming of ethanol to produce hydrogen for fuel cells, Chem. Eng. J. 117 (2006) 39-49.

[2] A. Haryanto, S. Fernando, N. Murali and S. Adhikari, Current status of hydrogen production techniques by steam reforming of ethanol: a review, Energy Fuels 19 (2005) 2098-2106.

[3] T. Aicher, J. Full and A. Schaadt, A portable fuel processor for hydrogen production from ethanol in a $250 \mathrm{Wel}$ fuel cell system, I. J. of Hydrogen Energy, doi:10.1016/j.ijhydene.2009.07.064.

[4] D. Markova, G. Bazbauers, K. Valters, R. Alhucema Arias, C. Weuffen and L. Rochlitz, Optimization of bio-ethanol autothermal reforming and carbon monoxide removal processes, I. J. of Power Sources, doi:10.1016/j.jpowsour.2009.01.095.

[5] D.R. Sahoo, S. Vajpai, S. Patel, K.K. Pant, Kinetic modeling of steam reforming of ethanol for the production of hydrogen over $\mathrm{Co} / \mathrm{Al}_{2} \mathrm{O}_{3}$ catalyst, Chem. Eng. J. 125 (3) (2007) 139-147.

[6] J.A Torres, J. Llorca, A. Casanovas, M. Domínguez, J. Salvadó and D.J. Montané, Steam reforming of ethanol at moderate temperature: Multifactorial design analysis of $\mathrm{Ni} / \mathrm{La}_{2} \mathrm{O}_{3}-\mathrm{Al}_{2} \mathrm{O}_{3}$, and $\mathrm{Fe}$ - and Mn-promoted $\mathrm{Co} / \mathrm{ZnO}$ catalysts, J. Power Sources 169 (1) (2007) 158-166. 
[7] A. Casanovas, M. Saint-Gerons, F. Griffon and J. Llorca, Autothermal generation of hydrogen from ethanol in a microreactor, Int. J. Hydrogen Energy 33 (7) (2008) 18271833.

[8] J. Llorca, A. Casanovas, T. Trifonov, A. Rodríguez and R. Alcubilla, First use of macroporous silicon loaded with catalyst film for a chemical reaction: A microreformer for producing hydrogen from ethanol steam reforming, J. Catal. 255 (2008) 228-233.

[9] V. M. García, E. López, M. Serra and J. Llorca, Dynamic modeling of a three-stage low-temperature ethanol reformer for fuel cell application, J. Power Sources 192 (1) (2009) 208-215.

[10] J. Pukrushpan, A. Stefanopoulou and H. Peng, Control of Fuel Cell Power Systems. Principles, Modeling, Analysis and Feedback Design, London: Springer (2004).

[11] W. F. Podolski and Y. G Kim, Modeling the Water-Gas Shift Reaction, Ind. Eng. Chem. 13 (4) (1974) 415-421.

[12] S. Skogestad and I. Postlethwaite, Multivariable Feedback Control, Analysis and Design, New York: John Wiley \& Sons (1996).

[13] K.E. Haggblom, American Control Conference, Washington, USA 11-13 June (2008) $5192-5197$.

[14] S. Elashhab. IEEE International Conference, Iowa, USA 18 - 20 May (2008) 6065.

\section{Figures}

Fig. 1 Schematic representation of the three-staged reforming process under study.

Fig. 2 Molar flow (solid lines) and yield of hydrogen (dotted lines) as function of the incremental input in $\mathrm{F}_{\mathrm{H} 2 \mathrm{O}, \mathrm{e}}$ and $\mathrm{F}_{\mathrm{C} 2 \mathrm{H} 5 \mathrm{OH}, \mathrm{e}}$. Model under $\mathrm{OP}_{1}$ operating conditions: isothermal operation at $\mathrm{T}_{\mathrm{e}}=648 \mathrm{~K}$, operating pressure of ca. 1 bar, $\mathrm{F}_{\mathrm{T}, \mathrm{e}}=0.09547 \mathrm{~mol} \mathrm{~s}^{-1}$,

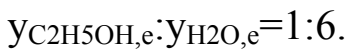


Fig. 3 Molar flow of carbon monoxide as function of the incremental input in $\mathrm{F}_{\mathrm{H} 2 \mathrm{O}, \mathrm{e}}$ and

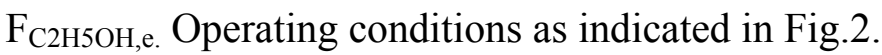

Fig. 4 Molar flow of carbon dioxide as function of the incremental input in $\mathrm{F}_{\mathrm{H} 2 \mathrm{O}, \mathrm{e}}$ and

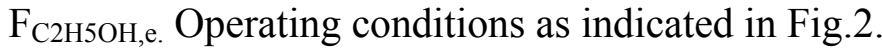

Fig. 5 Plot of $x_{\mathrm{C} 2 \mathrm{H} 5 \mathrm{OH}}$ and $x_{\mathrm{C} 2 \mathrm{H} 4 \mathrm{O}}$ as function of the incremental input in $\mathrm{F}_{\mathrm{H} 2 \mathrm{O}, \mathrm{e}}$ and $\mathrm{F}_{\mathrm{C} 2 \mathrm{H} 5 \mathrm{OH}, \mathrm{e}}$. Operating conditions as indicated in Fig.2.

Fig. 6 Hankel Singular Values of the $198^{\text {th }}$ order model and the detail of the first 20 values.

Fig. 7 Superposition of Bode plots for the reduced $10^{\text {th }}$ order model, in blue, and the linearized $198^{\text {th }}$ order model, in red.

Fig. 8 Relative Gain Array of the element $(1,1)$ for the different operating points in the frequency range $10^{-3}-10^{-1}\left[\mathrm{rad} \mathrm{s}^{-1}\right]$.

Fig. 9 Difference between diagonal and off-diagonal elements of the Relative Gain Array for three operating points in the frequency range $10^{-3}-10^{-1}\left[\mathrm{rad} \mathrm{s}^{-1}\right]$.

Fig. 10 Condition Number behavior at the different operating points in the frequency range $10^{-3}-10^{-1}\left[\mathrm{rad} \mathrm{s}^{-1}\right]$. 
Fig. 11 Morari Resiliency Index at the different operating points in the frequency range $10^{-3}-10^{-1}\left[\mathrm{rad} \mathrm{s}^{-1}\right]$. 